For mat $i$ on of Super oxi de Ani on during Fer rous I on- I nduced Decomposi ti on of Li nol ei c Aci d Hydroper oxi de under Aer obi c Condi ti ons

\begin{tabular}{|l|l|}
\hline 著者 & $\begin{array}{l}\text { Kanbayashi Yasuhi r, Ter o- Kubot a Shozo, } \\
\text { Yamannt o Yor i hi ro, Kat o Masashi, Nakano } \\
\text { M nor u, Yagi Kuni o, Ogi no Kei ki }\end{array}$ \\
\hline $\begin{array}{l}\text { j our nal or } \\
\text { publ i cat i on t i t l e }\end{array}$ & Jour nal of Bi ochem st ry \\
\hline vol une & 134 \\
\hline nunber & 6 \\
\hline page r ange & $903-909$ \\
\hline year & $2003-12-01$ \\
\hline URL & ht t p: //hdl . handl e. net /2297/14528 \\
\hline
\end{tabular}




\title{
Formation of Superoxide Anion during Ferrous Ion-Induced Decomposition of Linoleic Acid Hydroperoxide under Aerobic Conditions
}

\author{
Yasuhiro Kambayashi ${ }^{*}, 1,2$, Shozo Tero-Kubota ${ }^{3}$, Yorihiro Yamamoto ${ }^{4}$, Masashi Kato ${ }^{2}$, \\ Minoru Nakano', Kunio Yagi ${ }^{1}$ and Keiki Ogino ${ }^{2}$ \\ ${ }^{1}$ Department of Photon and Free Radical Research, Japan Immunoresearch Laboratories, 351-1 Nishiyokote-cho, \\ Takasaki 370-0021; ${ }^{2}$ Department of Environmental and Preventive Medicine, Graduate School of Medical Science, \\ Kanazawa University, 13-1 Takara-machi, Kanazawa 920-8640; ${ }^{3}$ Institute of Multidisciplinary Research for \\ Advanced Materials, Tohoku University, Sendai 980-8577; ${ }^{4}$ School of Bionics, Tokyo University of Technology, 1404- \\ 1 Katakura, Hachioji, Tokyo 192-0982; and ${ }^{5}$ Institute of Applied Biochemistry, Yagi Memorial Park, Mitake, Gifu \\ 505-0116
}

Received May 7, 2003; accepted October 22, 2003

We studied the mechanism of formation of oxygen radicals during ferrous ioninduced decomposition of linoleic acid hydroperoxide using the spin trapping and chemiluminescence methods. The formation of the superoxide anion $\left(\mathrm{O}_{2}^{--}\right)$was verified in the present study. The hydroxyl radical is also generated through Fenton type decomposition of hydrogen peroxide produced on disproportionation of $\mathrm{O}_{2}^{-{ }^{-}}$. A carbon-centered radical was detected using 5-(diethoxyphosphoryl)-5-methyl-1-pyrroline $\boldsymbol{N}$-oxide (DEPMPO) as a spin trap. Alkoxyl radical formation is essential for the conversion of linoleic acid hydroperoxide into the peroxyl radical by ferrous ion. It is likely that the alkoxyl radical $\left[\mathrm{R}_{1} \mathrm{CH}\left(\mathrm{O}^{-}\right) \mathrm{R}_{2}\right]$ is converted into the hydroxylcarbon radical $\left[R_{1} C \cdot(O H) R_{2}\right]$ in water, and that this carbon radical reacts with oxygen to give the a-hydroxyperoxyl radical $\left[\mathrm{R}_{1} \mathrm{R}_{2} \mathrm{C}(\mathrm{OH}) \mathrm{OO}\right]$, which decomposes into the carbocation $\left[\mathrm{R}_{1} \mathbf{C}^{+}(\mathrm{OH}) \mathrm{R}_{2}\right]$ and $\mathrm{O}_{2} \cdot-$.

Key words: ferrous ion-induced decomposition of linoleic acid hydroperoxide, hydrogen peroxide, hydroxyl radical, linoleic acid alkoxyl radical, superoxide anion.

\begin{abstract}
Abbreviations: DEPMPO, 5-(diethoxyphosphoryl)-5-methyl-1-pyrroline $N$-oxide; DEPMPO-OH, DEPMPOhydroxyl adduct; DEPMPO-OOH, superoxide anion adduct of DEPMPO; DMPO, 5,5-dimethyl-1-pyrroline $N$ oxide; DMPO-OH, DMPO-hydroxyl adduct; DMPO-OOH, superoxide anion adduct of DMPO; ESR, electron spin resonance; HPLC, high performance liquid chromatography; HX, hypoxanthine; LA, linoleic acid; LO; linoleic acid alkoxyl radical; LOH, linoleic acid hydroxide; LOO, linoleic acid peroxyl radical; LOOH, linoleic acid hydroperoxide; MCLA, 2-methyl-6-(p-methoxyphenyl)-3,7-dihydroimidazo[1,2-a]pyrazin-3-one; SOD, superoxide dismutase; XOD, xanthine oxidase.
\end{abstract}

The ferrous ion $\left(\mathrm{Fe}^{2+}\right)$-catalyzed decomposition of unsaturated fatty acid hydroperoxides is generally accepted to occur as shown in equation 1 , in which the alkoxyl type radical and hydoxyl anion are produced $(1,2)$.

$$
\mathrm{LOOH}+\mathrm{Fe}^{2+} \rightarrow \mathrm{LO}+\mathrm{OH}^{-}+\mathrm{Fe}^{3+}
$$

Using a spin trapping technique involving 5,5-dimethyl1 -pyrroline $N$-oxide (DMPO), however, Yagi et al. found that $\mathrm{Fe}^{2+}$-induced decomposition of linoleic acid hydroperoxide $(\mathrm{LOOH})$ generates the hydroxyl radical $(\cdot \mathrm{OH})$ under aerobic conditions (3). They suggested that $\mathrm{Fe}^{2+}$ causes homolytic cleavage of the O-O bond of LOOH (Eq. 2).

$$
\mathrm{LOOH}+\mathrm{Fe}^{2+} \rightarrow \mathrm{LO}+\mathrm{OH}+\mathrm{Fe}^{2+}
$$

However, it is unlikely that $\mathrm{Fe}^{2+}$ induces the homolysis of LOOH. There is a possibility that a consecutive chain reaction helps to yield $\mathrm{OH}$. Clarification of the reaction

"To whom correspondence should be addressed. Tel: +81-76-265-2217, Fax: +81-76-234-4233, E-mail: kambayashi@pub.m.kanazawa-u.ac.jp mechanism is important because the $\mathrm{Fe}^{2+}$-catalyzed decomposition of unsaturated fatty acid hydroperoxides is one of the most fundamental reactions in free radical biochemistry.

Schaich and Borg (4) and Chamulitrat et al. (5) also reported the formation of a spin adduct, which was comparable with the DMPO-OH adduct formed during the $\mathrm{Fe}^{2+}$-catalyzed decomposition of methyl linoleate hydroperoxide under aerobic conditions. However, they proposed a different mechanism from equation 1 . The former claimed that the electron spin resonance (ESR) spectrum of the DMPO-lipid alkoxyl radical spin adduct was identical to that of DMPO-OH. The latter claimed that most DMPO-OH was formed through ferric ion $\left(\mathrm{Fe}^{3+}\right)$-catalyzed nucleophilic addition of water to DMPO (6), and/or by the reaction between DMPO and $\mathrm{OH}$ produced via the Fenton reaction (7). These interpretations are in conflict. In these studies, only DMPO was used as the trapping reagent. Obviously, an ESR study with only one spin trap will not establish any mechanisms. For example, DMPO$\mathrm{OH}$ is formed in various ways, as mentioned below. The superoxide anion $\left(\mathrm{O}_{2}^{--}\right)$adduct of DMPO (DMPO-OOH) is a relatively short-lived spin adduct and is reduced to 
DMPO-OH within a few min (8). DMPO-OH is also formed through $\mathrm{Fe}^{2+}$-catalayzed decomposition of DMPO$\mathrm{OOH}(9)$. The reaction of singlet oxygen $\left({ }^{1} \mathrm{O}_{2}\right)$ with DMPO also gives DMPO-OH through a Fenton-like reaction $(10,11)$. Furthermore, DMPO-OH is produced under unexpected conditions such as on the $\mathrm{Fe}^{2+}-(12), \mathrm{Fe}^{3+}-(6)$, or $\mathrm{Fe}^{3+}$-bleomycin complex- (13) catalyzed oxidation of DMPO, or the photooxidation of DMPO (12). This makes it difficult to determine how DMPO-OH is produced. Recently, 5-(diethoxyphosphoryl)-5-methyl-1-pyrroline $N$-oxide (DEPMPO) was developed as a new spin trap (14). The $\mathrm{O}_{2} \cdot-$ spin adduct of DEPMPO (DEPMPO-OOH) is long-lived in comparison with DMPO-OOH $(14,15)$. Although DEPMPO-OH is observed in the presence of DEPMPO and $\mathrm{Fe}^{3+}$, a carbon-centered radical is also detected (16), unlike in the case where DMPO-OH is produced through $\mathrm{Fe}^{3+}$-catalyzed oxidation of DMPO. Therefore, DEPMPO is a useful spin trap for discriminating $\mathrm{OH}$ from $\mathrm{O}_{2}{ }^{-}$in a solution in which the two species coexist.

The present study was undertaken to verify the oxygen radical formation mechanism during the $\mathrm{Fe}^{2+}$-catalyzed decomposition of $\mathrm{LOOH}$ under aerobic conditions, using the ESR spin trapping technique and the 2-methyl-6-( $p$ methoxyphenyl)-3,7-dihydroimidazo[1,2-a]pyrazin-3-one (MCLA)-dependent chemiluminescence methods. We used DEPMPO in addition to DMPO as a spin trap in this study.

\section{MATERIALS AND METHODS}

Materials-DMPO, lipoxidase (Type 1-B), superoxide dismutase (SOD, from bovine erythrocytes), catalase (from bovine liver), and uric acid were purchased from Sigma Chemical (St. Louis, MO). DEPMPO was obtained from OXIS International (Portland, OR). Ferrous sulfate $\left(\mathrm{FeSO}_{4}\right)$ heptahydrate and ferric chloride $\left(\mathrm{FeCl}_{3}\right)$ hexahydrate were purchased from Wako Pure Chemical Industries (Osaka). Linoleic acid (LA) and MCLA were obtained from Tokyo Chemical Industry (Tokyo). Solvents and other reagents were of the highest grade commercially available. LA was purified by high performance liquid chromatography (HPLC) before use. 13-Hydroperoxy-9-cis,11-trans-octadecadienoic acid (linoleic acid hydroperoxide; LOOH) was prepared using LA and lipoxidase, and $\mathrm{LOOH}$ was reduced to alcohol $(\mathrm{LOH})$ with triphenylphosphine, and then the $\mathrm{LOOH}$ and $\mathrm{LOH}$ were purified by HPLC as previously described (17). The concentration of $\mathrm{LOOH}$ was determined using a hydroperoxide-specific, isoluminol chemiluminescence assay with HPLC (HPLC-CL) (18). The concentrations of LOOH and $\mathrm{LOH}$ were also determined using an assumed molar extinction coefficient at $234 \mathrm{~nm}, 28,000 \mathrm{M}^{-1} \mathrm{~cm}^{-1}$ (19). DMPO was purified by filtration with decolorizing activated carbon (Aldrich Chemical Company, Milwaukee, WI) immediately before use $(8,20)$. The concentration of DMPO was determined using an assumed molar extinction coefficient at $234 \mathrm{~nm}, 7,700 \mathrm{M}^{-1} \mathrm{~cm}^{-1}$ (21). DEPMPO was used without further purification. The concentration of DEPMPO was calculated from its molecular weight.

Spin Trapping of Free Radicals Produced during $\mathrm{Fe}^{2+}$. Catalyzed Decomposition of $\mathrm{LOOH}-\mathrm{A}$ reaction mixture $(450 \mu \mathrm{l})$ containing $2.5 \mathrm{mM} \mathrm{LOOH}$ and $613 \mathrm{mM}$ DMPO

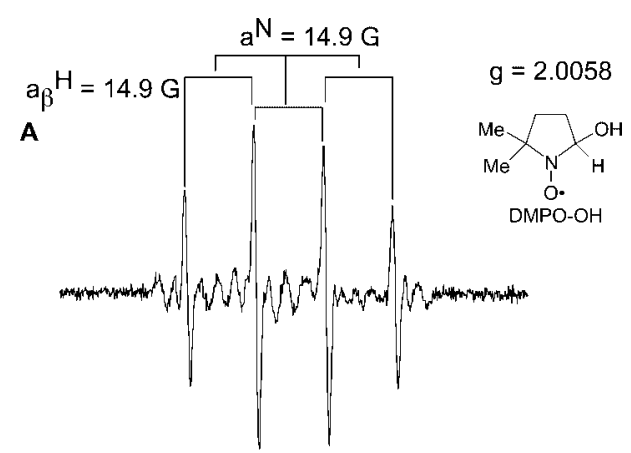

B
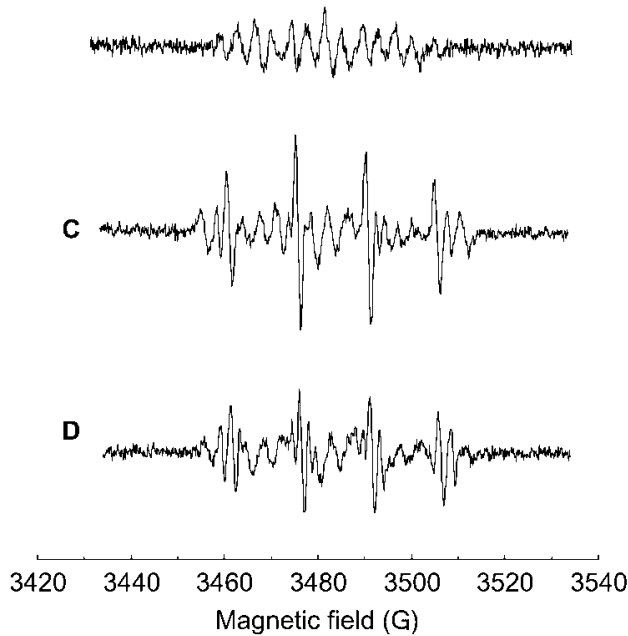

Fig. 1. ESR spectra of the DMPO-free radical spin adducts formed during the $\mathrm{Fe}^{2+}$-catalyzed decomposition of $\mathrm{LOOH}$, and the effects of SOD and catalase thereon. A: $2.2 \mathrm{mM} \mathrm{LOOH}$ $+100 \mu \mathrm{M} \mathrm{Fe}^{2+}+613 \mathrm{mM}$ DMPO, B: A - 2.2 mM LOOH, C: A + 0.5 $\mu \mathrm{M}$ SOD, D: A $+50 \mu \mathrm{g} / \mathrm{ml}$ catalase. Receiver gain: $2.5 \times 10^{5}$; modulation frequency: $100 \mathrm{kHz}$; modulation amplitude: $1.011 \mathrm{G}$; conversion: $81.920 \mathrm{~ms}$; time constant: $40.960 \mathrm{~ms}$; sweep time: $83.883 \mathrm{~s}$; microwave frequency: $9.779 \mathrm{GHz}$; microwave power: $7.73 \mathrm{~mW}$; scan number: $\times 10$.

was prepared in $50 \mathrm{mM}$ potassium phosphate buffer $(\mathrm{pH}$ 7.4) pretreated with CHELEX 100 (BIO-RAD Laboratories, Hercules, CA). LOOH-decomposition was initiated by the addition of $\mathrm{FeSO}_{4}$ (final concentration: $100 \mu \mathrm{M}$ ) at $25^{\circ} \mathrm{C}$ under aerobic conditions. LA or LOH was also used instead of LOOH. If necessary, SOD $(0.5 \mu \mathrm{M})$, catalase $(50 \mu \mathrm{g} / \mathrm{ml})$, ethanol $(16.7 \%)$, sodium azide $(1 \mathrm{mM})$, or uric acid $(100 \mu \mathrm{M})$ was added to the reaction mixture. $\mathrm{FeCl}_{3}$ and DEPMPO (20 or $40 \mathrm{mM}$ ) were used instead of $\mathrm{FeSO}_{4}$ and DMPO, respectively. An aliquot of the reaction mixture was transferred to a flat cell and ESR signals were measured with a BRUKER ESR spectrometer (ESP $300 \mathrm{E}$. Karlsruhe, Germany) at $25^{\circ} \mathrm{C}$. The measurement conditions are given in each figure legend. To avoid photo-induced reactions, sample preparation and measurements were carried out under weak red light. If necessary, argon gas was introduced into a solution for $2 \mathrm{~h}$ under a nitrogen atmosphere in a glove box prior to the measurement. A reaction solution was transferred to a flat cell. ESR signals were measured at $25^{\circ} \mathrm{C}$ under atmospheric air after the flat cell had been sealed with a teflon seal under a nitrogen atmosphere. 
A
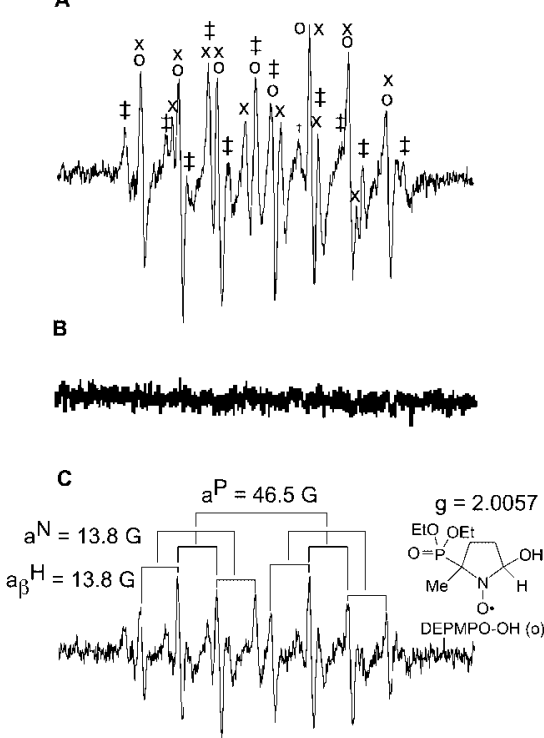

340034203440346034803500352035403560 Magnetic field (G)

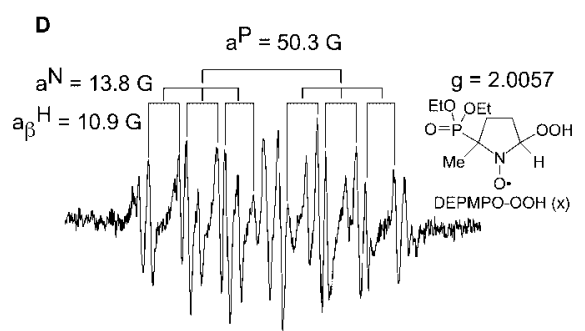

E

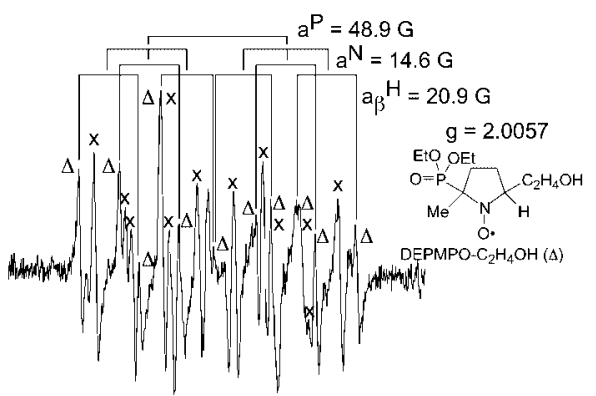

340034203440346034803500352035403560 Magnetic field $(\mathrm{G})$
Fig. 2. ESR spectra of the DEPMPOfree radical spin adducts formed during the $\mathrm{Fe}^{2+}$-catalyzed decomposition of $\mathrm{LOOH}$, and the effects of SOD, catalase, and ethanol thereon. $\mathrm{o}, \mathrm{x}, \ddagger$, and $\Delta$ represent the DEPMPO-OH spin adduct, DEPMPO$\mathrm{OOH}$ spin adduct, DEPMPO-carboncentered radical adduct, and DEPMPOhydroxyethyl spin adduct, respectively. A: $2.2 \mathrm{mM} \mathrm{LOOH}+100 \mu \mathrm{M} \mathrm{Fe}^{2+}$ $+40 \mathrm{mM}$ DEPMPO, B: A $-2.2 \mathrm{mM}$ LOOH, C: A + $0.5 \mu \mathrm{M}$ SOD, D: A + 50 $\mu \mathrm{g} / \mathrm{ml}$ catalase, $\mathrm{E}: \mathrm{A}+16.7 \%$ ethanol. Receiver gain: $2.5 \times 10^{5}$; modulation frequency: $100 \mathrm{kHz}$; modulation amplitude: $1.011 \mathrm{G}$; conversion: $81.920 \mathrm{~ms}$; time constant: $40.960 \mathrm{~ms}$; sweep time: $83.883 \mathrm{~s}$; microwave frequency: 9.779 $\mathrm{GHz}$; microwave power: $23.9 \mathrm{~mW}$; scan number: $\times 10$.
Chemiluminescence during $\mathrm{Fe}^{2+}$-Catalyzed Decomposition of $\mathrm{LOOH}-\mathrm{A}$ reaction mixture $(1 \mathrm{ml})$ comprising 50 $\mu \mathrm{M}$ LOOH and $10 \mu \mathrm{M}$ MCLA in $50 \mathrm{mM}$ potassium phosphate buffer ( $\mathrm{pH}$ 7.4) pretreated with CHELEX 100 was placed in a luminescence reader (Type; BLR-301, Aloka, Tokyo). Chemiluminescence was detected after the addition of $\mathrm{FeSO}_{4}$ (final concentration: $2 \mu \mathrm{M}$ ) at $25^{\circ} \mathrm{C}$ under aerobic conditions. If necessary, $\operatorname{SOD}(0.5 \mu \mathrm{M})$, catalase $(20 \mu \mathrm{g} / \mathrm{ml})$, sodium azide $(1 \mathrm{mM})$, and/or DMPO $(12 \mathrm{mM})$ were added to the reaction mixture. $\mathrm{LA}$ or $\mathrm{LOH}$ was also used instead of LOOH. Various concentrations of LA, $\mathrm{LOH}, \mathrm{LOOH}$, or $\mathrm{FeSO}_{4}$ were also used, as described in the figure legends. If necessary, argon gas was introduced into a solution under atmospheric air for $30 \mathrm{~min}$ prior to the measurement. The effect of the $\mathrm{FeSO}_{4} / \mathrm{FeCl}_{3}(\mathrm{Fe}=2$ $\mu \mathrm{M})$ ratio on chemiluminescence intensity was also examined.

Yield of $\mathrm{O}_{2}^{\cdot-}$ during $\mathrm{Fe}^{2+}$ Catalyzed Decomposition of LOOH-Hypoxanthine (HX; $1 \times 10^{-3} \mathrm{U} / \mathrm{ml}, 5 \times 10^{-3} \mathrm{U} / \mathrm{ml}$, or $1 \times 10^{-3} \mathrm{U} / \mathrm{ml}$ ) and xanthine oxidase (XOD; $40 \mu \mathrm{M}$ ) were incubated with cytochrome $c(50 \mu \mathrm{M})$ at $25^{\circ} \mathrm{C}$, the change in absorbance of cytochrome $c$ at $550 \mathrm{~nm}$ being monitored. The amount of $\mathrm{O}_{2}{ }^{-}$formed was calculated using the molar extinction coefficient of a reduced form of cytochrome $c$ at $550 \mathrm{~nm}\left[21,100 \mathrm{M}^{-1} \mathrm{~cm}^{-1}(22)\right]$. The values were compared with the integrated MCLA-dependent chemiluminescence intensity obtained under the same conditions except that MCLA $(10 \mu \mathrm{M})$ was used instead of cytochrome $c$ and the amount of $\mathrm{O}_{2} \cdot{ }^{-}$formed per chemiluminescence intensity was calculated.

Chemiluminescence intensity was measured during 2 $\mu \mathrm{M} \mathrm{Fe}^{2+}$-catalyzed decomposition of $36 \mu \mathrm{M} \mathrm{LOOH}$ with 10 $\mu \mathrm{M}$ MCLA in the presence or absence of $0.5 \mu \mathrm{M}$ SOD at $25^{\circ} \mathrm{C}$. The change in LOOH was monitored by HPLC-CL during $2 \mu \mathrm{M} \mathrm{Fe}^{2+}$-induced decomposition of $36 \mu \mathrm{M} \mathrm{LOOH}$, and the amount of $\mathrm{LOOH}$ decomposed during the present reaction was obtained. The yield of $\mathrm{O}_{2} \cdot-$ during $\mathrm{Fe}^{2+}$-catalyzed decomposition of $\mathrm{LOOH}$ was calculated with the values obtained in the above experiments. $\left[\mathrm{O}_{2}{ }^{\cdot-}\right.$ formed] was calculated from the SOD-sensitive MCLA-dependent chemiluminescence intensity.

$$
\begin{aligned}
& \text { Yield of } \mathrm{O}_{2} \cdot-(\%) \\
& =\left[\mathrm{O}_{2} \cdot{ }^{-} \text {formed }\right](\mu \mathrm{M}) /[\mathrm{LOOH} \text { decreased }](\mu \mathrm{M}) \times 100
\end{aligned}
$$

\section{RESULTS}

Spin Trapping of Free Radicals Produced during $\mathrm{Fe}^{2+}$. Catalyzed Decomposition of LOOH under Aerobic Conditions-Fig. 1A shows the ESR spectrum obtained during the $\mathrm{Fe}^{2+}$-induced decomposition of $\mathrm{LOOH}$ in the presence of DMPO. The hyperfine splitting constants of major signals were $a^{\mathrm{N}}=a_{\beta}{ }^{\mathrm{H}}=14.9 \mathrm{G}, g=2.0058$, which were identical with those of DMPO-OH $\left(a^{\mathrm{N}}=a_{\beta}{ }^{\mathrm{H}}=15.0 \mathrm{G}, g=\right.$ 2.0062) (23). The DMPO-OH signal was not observed when $\mathrm{LOOH}$ was removed from the above system (Fig. 1B). The DMPO-OH signal intensity was decreased with the addition of SOD (Fig. 1C) and was substantially decreased on the addition of catalase (Fig. 1D). Chamulitrat et al. reported comparable results with catalase, although they used methyl linoleate hydroperoxide instead of $\mathrm{LOOH}$ (5). Separate experiments involving HPLC-CL showed that catalase $(50 \mu \mathrm{g})$ did not decompose $\mathrm{LOOH}$ to the linoleic acid alkoxyl radical (LO) or linoleic acid peroxyl radical (LOO) (data not shown).

To obtain clearer ESR signals, we used DEPMPO as a spin trap instead of DMPO. Fig. 2A shows the ESR spectrum obtained during the $\mathrm{Fe}^{2+}$-catalyzed decomposition of $\mathrm{LOOH}$ in the presence of DEPMPO under aerobic conditions. The ESR spectrum consists of the signals of three kinds of spin adducts: the DEPMPO-hydroxyl adduct $($ DEPMPO-OH $)\left(o ; a^{\mathrm{N}}=14.0 \mathrm{G}, a_{\beta}{ }^{\mathrm{H}}=13.0 \mathrm{G}, a^{\mathrm{P}}=47.4 \mathrm{G}, g\right.$ $=2.0059)(14)$, the DEPMPO-OOH adduct $\left(\mathrm{x} ; a^{\mathrm{N}}=13.4 \mathrm{G}\right.$, $\left.a_{\beta}{ }^{\mathrm{H}}=11.9 \mathrm{G}, a^{\mathrm{P}}=52.5 \mathrm{G}, g=2.0059\right)(14)$, and the carboncentered spin adduct of DEPMPO $\left(\ddagger ; a^{\mathrm{N}}=14.5 \mathrm{G}, a_{\beta}{ }^{\mathrm{H}}=\right.$ $\left.22.0 \mathrm{G}, a^{\mathrm{P}}=46.0 \mathrm{G}, g=2.0061\right)$. The assignment of each 


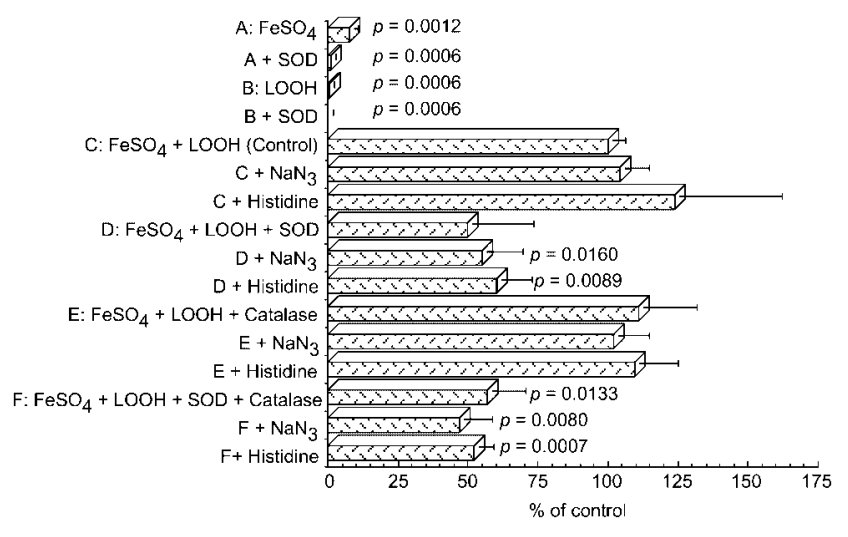

Fig. 3. The effects of SOD $(0.5 \mu \mathrm{M})$, catalase $(20 \mu \mathrm{g} / \mathrm{ml})$, sodium azide $(1 \mathrm{mM})$, and/or histidine $(10 \mathrm{mM})$ on the chemiluminescence observed during the $2 \mu \mathrm{M} \mathrm{Fe}^{2+}$-catalyzed decomposition of $50 \mu \mathrm{M} \mathrm{LOOH}$ in the presence of $10 \mu \mathrm{M}$ MCLA at $25^{\circ} \mathrm{C}$ under atomospheric air. The $P$ values were obtained by comparison with a control, using a paired t test.

was confirmed by means of quenching reactions with SOD, catalase and ethanol, as described below. These signals were not observed when DEPMPO was incubated with only $\mathrm{Fe}^{2+}$ (Fig. 2B). The addition of SOD reduced the DEPMPO-OOH signal intensity (x; Fig. 2C). The addition of catalase substantially decreased the DEPMPO-OH signal intensity (o; Fig. 2D). The addition of ethanol to the reaction mixture as an $\mathrm{OH}$ scavenger gave the ESR spectrum shown in Fig. 2E. The signals enhanced by the addition of ethanol were identified as those of the DEPMPO adduct of the hydroxyethyl radical $[\Delta$; DEPMPO-CH $\left.\left(\mathrm{CH}_{3}\right) \mathrm{OH}\right]\left(a^{\mathrm{N}}=14.6 \mathrm{G}, a_{\beta}{ }^{\mathrm{H}}=21.1 \mathrm{G}, a^{\mathrm{P}}=\right.$ $49.6 \mathrm{G}, g=2.0058$; our unpublished data). The ESR parameters of DEPMPO- $\mathrm{CH}\left(\mathrm{CH}_{3}\right) \mathrm{OH}$ are nearly identical to those of the carbon-centered spin adduct of DEPMPO obtained in the decomposition reaction. The present spin trapping experiments suggest the generation of $\mathrm{O}_{2}^{\cdot-}, \mathrm{OH}, \mathrm{H}_{2} \mathrm{O}_{2}$, and the carbon-centered radical during the $\mathrm{Fe}^{2+}$-catalyzed decomposition of $\mathrm{LOOH}$ under aerobic conditions.

Chemiluminescence during $\mathrm{Fe}^{2+}$-Catalyzed Decomposition of LOOH under Aerobic Conditions-The formation of $\mathrm{O}_{2}^{--}$during the present reaction was also examined using MCLA, which is a specific chemiluminescence probe for $\mathrm{O}_{2}{ }^{-}$and ${ }^{1} \mathrm{O}_{2}(24)$. Fig. 3 depicts the relative intensity of MCLA-dependent chemiluminescence observed during the $\mathrm{Fe}^{2+}$-catalyzed decomposition of $\mathrm{LOOH}$ under various conditions. The addition of SOD to the control reaction mixture significantly decreased the MCLA-dependent chemiluminescence intensity, suggesting the involvement of $\mathrm{O}_{2}^{-}$formation. Since catalase, sodium azide and histidine did not affect the chemiluminescence intensity, hydrogen peroxide $\left(\mathrm{H}_{2} \mathrm{O}_{2}\right)$ and ${ }^{1} \mathrm{O}_{2}$
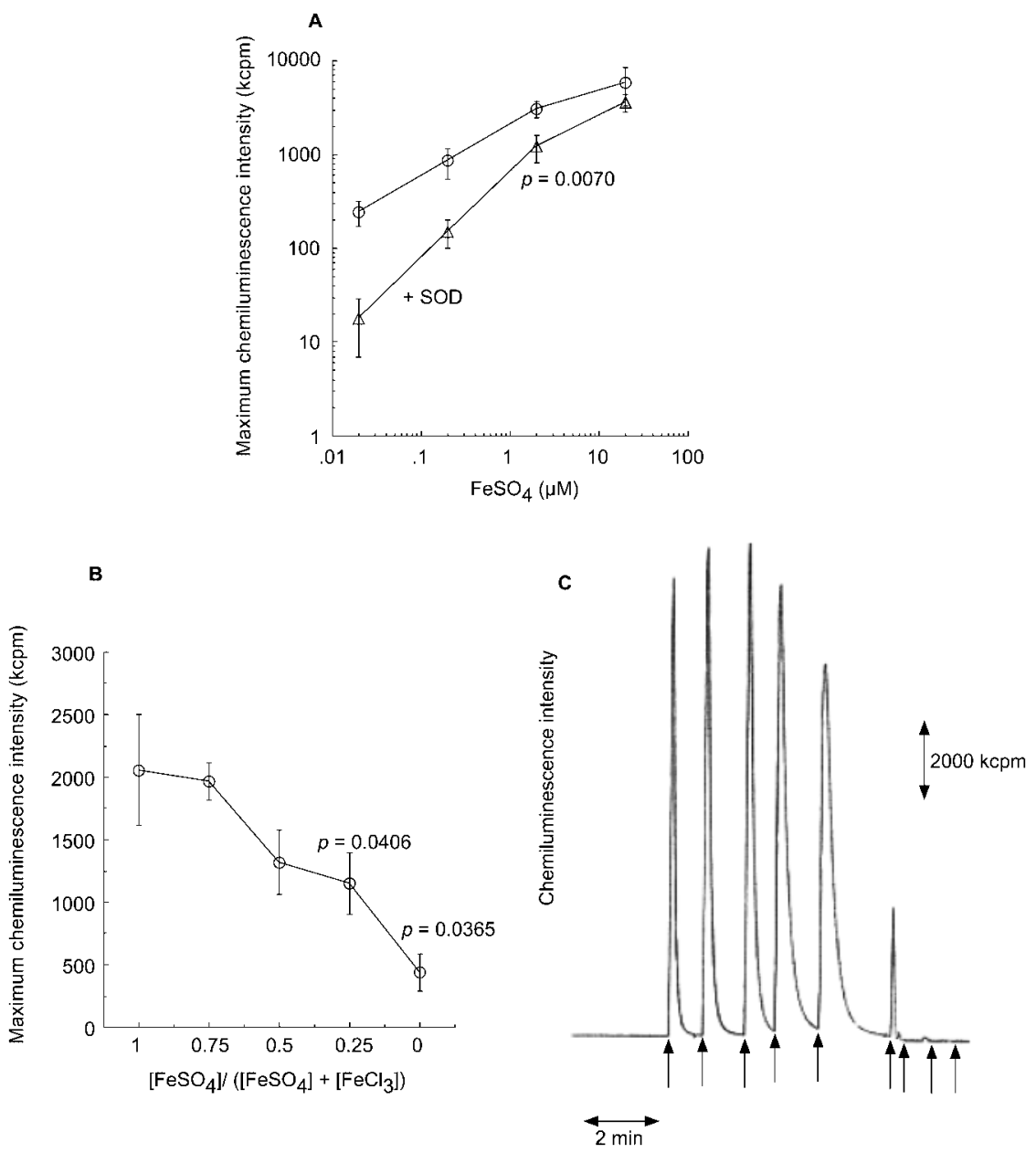

Fig. 4. (A) The effects of the $\mathrm{Fe}^{2+}$ concentration on the MCLA-dependent chemiluminescence observed during the ferrous ion-catalyzed decomposition of 50 $\mu \mathrm{M} \mathrm{LOOH}$ at $25^{\circ} \mathrm{C}$ in the presence $(\Delta)$ and absence (o) of SOD. The $P$ values were obtained through a paired $t$ test, that compared the results in the presence and absence of SOD. (B) The effect of the ratio between $\mathrm{FeSO}_{4}$ and $\mathrm{FeCl}_{3}(\mathrm{Fe}=2 \mu \mathrm{M})$ on the chemiluminescence intensity observed during the iron-catalyzed decomposition of $50 \mu \mathrm{M}$ LOOH. The $P$ values were obtained through a paired t test involving comparison with the $\mathrm{FeSO}_{4}$ (without $\mathrm{FeCl}_{3}$ ) system. (C) Chemiluminescence observed in the presence of $10 \mu \mathrm{M}$ MCLA, $50 \mu \mathrm{M}$ LOOH, and $\mathrm{FeSO}_{4}$ in 50 mM potassium phosphate buffer $(\mathrm{pH}$ 7.4) at $25^{\circ} \mathbf{C} .20 \mu \mathrm{M} \mathrm{FeSO}_{4}$ was added at each point indicated by an arrow. 


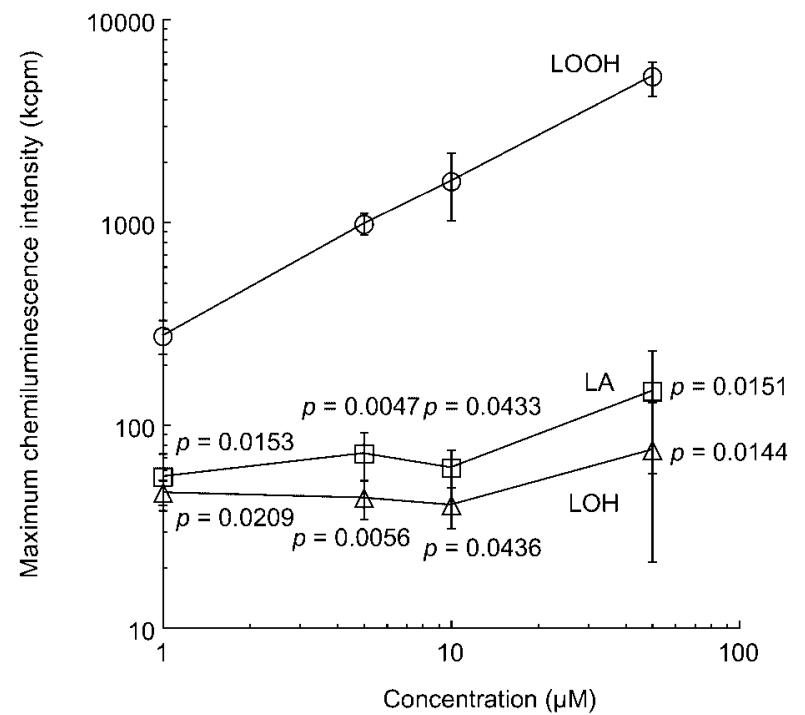

Fig. 5. The effects of the LA, LOH and LOOH concentrations on the MCLA-dependent chemiluminescence observed during the reaction between $2 \mu M$ ferrous ion and LA, LOH, and LOOH at $25^{\circ} \mathbf{C}$. The $P$ values were obtained through a paired t test involving comparison with the $\mathrm{LOOH}$ system.

were not contributors to the emission. Judging from the time-dependent change in the $\mathrm{LOOH}$ concentration [as monitored by HPLC-CL (18)], the $\mathrm{Fe}^{2+}$-catalyzed decomposition of $\mathrm{LOOH}$ in potassium phosphate buffer stopped within an extremely short time (data not shown), probably because $\mathrm{Fe}^{2+}$ was chelated by phosphate and/or converted to ferric hydroxide $\left[\mathrm{Fe}(\mathrm{OH})_{3}\right]$, which is poorly soluble in water (1). The addition of DMPO (12 mM) had no effect on the chemiluminescence intensity (data not shown). This was due to the relatively small second-order rate constant of the reaction between $\mathrm{O}_{2}{ }^{--}$and DMPO (10 $\mathrm{M}^{-1} \mathrm{~s}^{-1}$ at $\left.\mathrm{pH} 7.8,25^{\circ} \mathrm{C}\right)(25)$ in comparison with that of the reaction between MCLA and $\mathrm{O}_{2}^{--}\left(2.2 \times 10^{5} \mathrm{M}^{-1} \mathrm{~s}^{-1}\right.$ at $\mathrm{pH} 7,20^{\circ} \mathrm{C}$; K. Akutsu and K. Fujimori, unpublished data).

Strong emission was not observed for the system with $\mathrm{MCLA}+\mathrm{Fe}^{2+}$ or MCLA + LOOH. The chemiluminescence intensity observed during the decomposition of $\mathrm{LOOH}$ by $\mathrm{Fe}^{2+}$ was dependent on the $\mathrm{FeSO}_{4}$ concentration (Fig. 4A). SOD decreased the chemiluminescence intensity but DMPO did not (data not shown). The effect of the ratio between $\mathrm{FeSO}_{4}$ and $\mathrm{FeCl}_{3}$ on the chemiluminescence observed during the $2 \mu \mathrm{M}$ iron-catalyzed decomposition of $\mathrm{LOOH}$ was examined (Fig. 4B). When more $\mathrm{FeSO}_{4}$ was in the reaction mixture, stronger chemiluminescence was observed. Moreover, the addition of $0.1-0.4 \mu \mathrm{M} \mathrm{FeCl}_{3}$ to the reaction mixture containing $2 \mu \mathrm{M} \mathrm{FeSO}{ }_{4}, 50 \mu \mathrm{M}$ $\mathrm{LOOH}$, and $10 \mu \mathrm{M}$ MCLA had no effect on the chemiluminescence intensity (data not shown). On the other hand, chemiluminescence was observed whenever $20 \mu \mathrm{M} \mathrm{FeSO}_{4}$ was added to the solution containing $10 \mu \mathrm{M}$ MCLA and $50 \mu \mathrm{M}$ LOOH until LOOH was completely decomposed (Fig. 4C). MCLA was not completely consumed during this experiment (data not shown). These results suggest that $\mathrm{FeSO}_{4}$, not $\mathrm{FeCl}_{3}$, was necessary for $\mathrm{O}_{2}{ }^{--}$production. The intensity of the chemiluminescence was also dependent on the LOOH concentration (Fig. 5). Concentration-
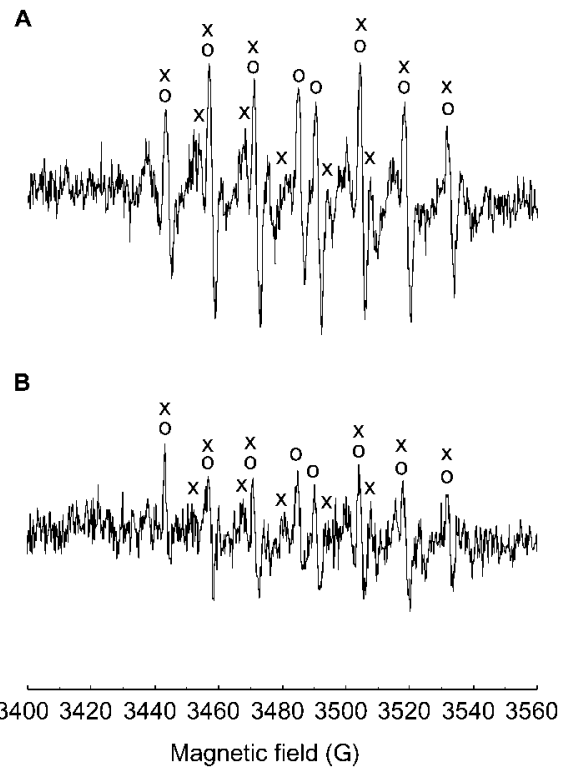

Fig. 6. The effect of argon gas on the DEPMPO-OOH signal intensity obtained during the $100 \mu \mathrm{M}$ ferrous ion-catalyzed decomposition of $2.2 \mathrm{mM} \mathrm{LOOH}$ in the presence of $20 \mathrm{mM}$ DEPMPO at $25^{\circ} \mathrm{C}$. ESR spectra were measured at $25^{\circ} \mathrm{C}$ under atmospheric air. $o$ and $\mathrm{x}$ represent the DEPMPO-OH spin adduct and DEPMPO-OOH spin adduct, respectively. A: No treatment, B: Argon gas bubbling. Receiver gain: $5.0 \times 10^{5}$; modulation frequency: $100 \mathrm{kHz}$; modulation amplitude: $2.018 \mathrm{G}$; conversion: $81.920 \mathrm{~ms}$; time constant: $40.960 \mathrm{~ms}$; sweep time: $83.886 \mathrm{~s}$; microwave frequency: $9.779 \mathrm{GHz}$; microwave power: $9.7 \mathrm{~mW}$; scan number: $\times 20$.

dependency of the chemiluminescence intensity was, however, not observed when LA or LOH was used instead of LOOH. Also, an ESR signal was not observed for the system with LA or LOH (data not shown). These results show that $\mathrm{LOOH}$ is necessary for the production of $\mathrm{O}_{2}^{-{ }^{-}}$in this system, and hydroperoxide, not carboxylic groupcontaining compounds for chelating iron, is important for the production of $\mathrm{O}_{2}{ }^{-}$- during the $\mathrm{Fe}^{2+}$-catalyzed decomposition of LOOH. Comparable but weak ESR signals and MCLA-dependent chemiluminescence were observed when $\mathrm{Fe}^{3+}$ was used instead of $\mathrm{Fe}^{2+}$ (data not shown).

Yield of $\mathrm{O}_{2}{ }^{--}$during $\mathrm{Fe}^{2+}$-Catalyzed Decomposition of $\mathrm{LOOH}-\mathrm{We}$ estimated the approximate ratio of $\mathrm{O}_{2}{ }^{-}$ formed to LOOH decomposed. One count of MCLAdependent chemiluminescence intensity corresponded to $1 \mathrm{fmol} / \mathrm{ml}$ of $\mathrm{O}_{2} \cdot$ - formed. The integrated MCLA-dependent chemiluminescence intensity obtained during the 2 $\mu \mathrm{M} \mathrm{Fe} e^{2+}$-catalyzed decomposition of $36 \mu \mathrm{M} \mathrm{LOOH}$ was $127 \pm 26$ kcounts (mean $\pm \mathrm{SD}, n=3$ ). In the presence of $0.5 \mu \mathrm{M}$ SOD, the integrated chemiluminescence intensity was $23 \pm 5$ kcounts (mean $\pm \mathrm{SD}, n=3$ ). The difference was 104 kcounts. This corresponds to $104 \mathrm{pmol} / \mathrm{ml}$ of $\mathrm{O}_{2}{ }^{-}-$ formed. Since $10 \%$ of $\mathrm{LOOH}$ was decomposed during the reaction (data not shown), the $\mathrm{O}_{2}{ }^{-}$formed in this system corresponded to $2.9 \%$ of $\mathrm{LOOH}$ decomposed.

Effect of Argon Gas in the Solvent on the Intensity of the Spin Adduct Formed during $\mathrm{Fe}^{2+}$-Catalyzed Decomposition of $\mathrm{LOOH}$-Figure 6 shows the effect of argon gas, introduced into the solvent, on the formation of $\mathrm{O}_{2}{ }^{--}$during the $\mathrm{Fe}^{2+}$-catalyzed decomposition of $\mathrm{LOOH}$. Argon gas bubbled into each solution for $2 \mathrm{~h}$ under a nitrogen 


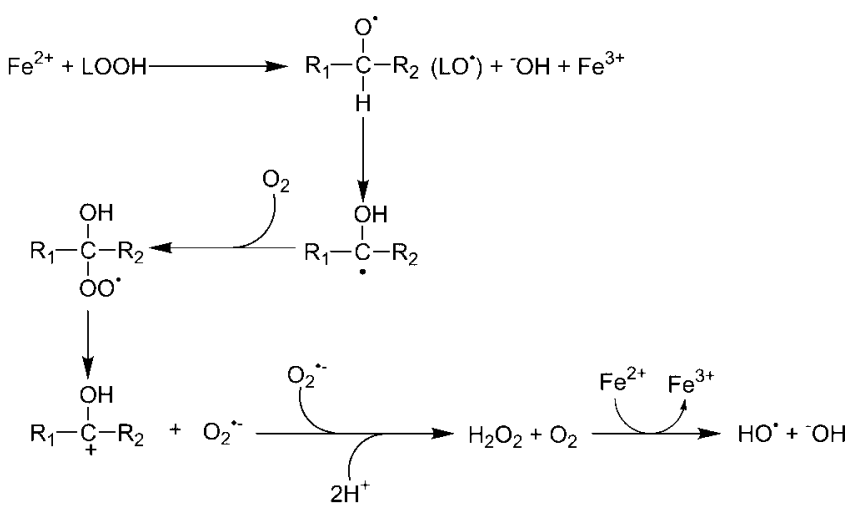

Scheme 1. Proposed mechanism for the formation of the superoxide anion and other active oxygen species during the ferrous ion-catalyzed decomposition of linoleic acid hydroperoxide under aerobic conditions.

atmosphere decreased the ESR signal intensities of DEPMPO adducts (DEPMPO-OOH: $a_{\beta}{ }^{\mathrm{H}}=10.7 \mathrm{G}, a^{\mathrm{N}}=$ $13.8 \mathrm{G}, a^{\mathrm{P}}=50.0 \mathrm{G} ;$ DEPMPO-OH: $a_{\beta}{ }^{\mathrm{H}}=13.8 \mathrm{G}, a^{\mathrm{N}}=13.6$ $\left.\mathrm{G}, a^{\mathrm{P}}=46.9 \mathrm{G}\right)$. A weak ESR signal was observed in this case since oxygen might remain in the solution and/or the $\mathrm{Fe}^{3+}$-catalyzed nucleophilic attack of water on DEPMPO might occur. The intensity of MCLA-dependent chemiluminescence observed during the $\mathrm{Fe}^{2+}$-catalyzed decomposition of $\mathrm{LOOH}$ was also decreased to two-thirds by argon gas bubbling for $30 \mathrm{~min}$ under atmospheric air (data not shown).

\section{DISCUSSION}

The present study has shown that $\mathrm{O}_{2}^{-{ }^{-}}, \mathrm{H}_{2} \mathrm{O}_{2}, \mathrm{OH}$, and the carbon-centered radical are formed during the $\mathrm{Fe}^{2+}$ catalyzed decomposition of $\mathrm{LOOH}$ under aerobic conditions. Therefore, DMPO-OH is suggested to be formed through the reaction between DMPO and $\mathrm{OH}$ produced via the Fenton reaction. Catalase, however, did not suppress the formation of DMPO-OH and DEPMPO-OH completely. Parts of the observed DMPO-OH and DEPMPO-OH might be produced via other pathways. Koga et al. reported (26) that ${ }^{1} \mathrm{O}_{2}$ is formed during the $\mathrm{Fe}^{3+}$-catalyzed decomposition of $\mathrm{LOOH}$, probably via the Russell mechanism (27). The formation of DMPO-OH during the reaction between DMPO and ${ }^{1} \mathrm{O}_{2}$ has also been reported $(10,11)$. However, no effect of an ${ }^{1} \mathrm{O}_{2}$ quencher (sodium azide, uric acid, or histidine) on the ESR signal (data not shown) or chemiluminescence intensity was observed in the present study. Schaich and Borg reported that the spectrum of the DMPO-lipid alkoxyl radical was identical to that of DMPO-OH (4), but this appears not to be correct since the DMPO-linoleic acid alkoxyl radical spin adduct spectrum reported recently (28) was different from the DMPO-OH spectrum.

The main radical species formed during the $\mathrm{Fe}^{2+}$-catalyzed decomposition of $\mathrm{LOOH}$ is $\mathrm{LO}(1,2)$. Therefore, MCLA may react with LO, the MCLA radical may be formed, and light may be emitted, although MCLA is known as a specific probe for the chemiluminescent detection of $\mathrm{O}_{2} \cdot{ }^{-}$and ${ }^{1} \mathrm{O}_{2}(24)$. Since the reaction between the MCLA radical and molecular oxygen is significantly slower than that of dimerization of the MCLA radical (29), MCLA does not react with oxygen to emit light in the present system. Therefore, the MCLA-dependent chemiluminescence observed in this study was caused by $\mathrm{O}_{2}^{--}$.

Since each ESR spectrum was obtained by the accumulation of ten spectra obtained consecutively (each scan took $83.883 \mathrm{~s}$ ), measurement was continued after the reaction had been stopped. On the other hand, the halflife of DMPO-OOH is $60 \mathrm{~s}$ (25) and that of DEPMPO$\mathrm{OOH}$ is $890 \mathrm{~s}$ (14). Therefore, DMPO-OOH decomposed into DMPO-OH during the measurement and DEPMPO$\mathrm{OOH}$ remained. For these reasons, the DEPMPO-OOH spin adduct, but not the DMPO-OOH one, might be observed during the $\mathrm{Fe}^{2+}$-catalyzed decomposition of $\mathrm{LOOH}$.

The present study has shown that $\mathrm{LOOH}$ was needed for the formation of $\mathrm{O}_{2}{ }^{-}$- during the decomposition of $\mathrm{LOOH}$ by $\mathrm{Fe}^{2+}$. Our results also show that $\mathrm{Fe}^{2+}$ was needed for $\mathrm{O}_{2}^{-}$formation. The $\mathrm{Fe}^{2+}$-catalyzed reduction of triplet oxygen to $\mathrm{O}_{2}{ }^{-}$(1) contributed only slightly to the formation of $\mathrm{O}_{2}{ }^{-}$in the present study (Figs. 1-3). On the other hand, introducing argon gas into the solvent reduced the intensity of both the ESR signal (Fig. 6) and the MCLA-dependent chemiluminescence (data not shown) observed during the $\mathrm{Fe}^{2+}$-catalyzed decomposition of $\mathrm{LOOH}$. These results suggest that oxygen dissolved in the solution, in addition to the reaction intermediate generated during the decomposition of $\mathrm{LOOH}$, plays an important role in the production of $\mathrm{O}_{2}{ }^{-}$in the present reaction system.

Recently, it was suggested that primary alkoxyl radicals $\left(\mathrm{RCO}^{+}\right)$are converted into $\alpha$-hydroxylcarbon-centered radicals through an unusual 1,2-H-atom shift in the presence of water (30), and the carbon-centered radicals react with dioxygen to yield $\alpha$-hydroxyperoxyl radicals $(30,31)$. It is well known that a number of peroxyl radicals decompose into carbocations and $\mathrm{O}_{2}{ }^{-}$. Therefore, we tentatively propose the mechanism of $\mathrm{O}_{2} \cdot$ - formation shown in Scheme 1. Conversion of $\mathrm{LO}\left[\mathrm{R}_{1} \mathrm{CH}\left(\mathrm{O}^{+}\right) \mathrm{R}_{2}\right]$ into a hydroxycarbon-centered radical $\left[\mathrm{R}_{1} \mathrm{C}^{+}(\mathrm{OH}) \mathrm{R}_{2}\right]$ in water may occur, although it is a secondary alkoxyl radical. In fact, a carbon-centered radical was detected during the $\mathrm{Fe}^{2+}$-catalyzed decomposition of $\mathrm{LOOH}$ under anaerobic conditions (32). In the present spin trapping experiments involving DEPMPO, the carbon-centered radical was also detected during the reaction. Then, the hydroxyperoxy radical $\left[\mathrm{R}_{1} \mathrm{COO}(\mathrm{OH}) \mathrm{R}_{2}\right]$ formed through the reaction between this carbon-centered radical and molecular oxygen may decompose into a carbocation $\left[\mathrm{R}_{1} \mathrm{C}^{+}(\mathrm{OH}) \mathrm{R}_{2}\right]$ and $\mathrm{O}_{2}{ }^{--}$.

Finally, in this study we have demonstrated for the first time the mechanism of formation of $\mathrm{O}_{2}{ }^{-}$(as distinct from the $\mathrm{Fe}^{2+}$-catalyzed reduction of oxygen) during the $\mathrm{Fe}^{2+}$-induced decomposition of $\mathrm{LOOH}$ under aerobic conditions.

We wish to thank Dr. Yasuhiro Kobori of Tohoku University for the advice to Y.K. regarding the ESR technique. 


\section{REFERENCES}

1. Halliwell, B. and Gutteridge, J.M.C. (1999) Free Radicals in Biology and Medicine Third Edition, Oxford University Press, New York and Oxford

2. O'Brien, P.J. (1969) Intracellular mechanisms for the decomposition of a lipid peroxide. I. Decomposition of a lipid peroxide by metal ions, heme compounds, and nucleophiles. Can. J. Biochem. 47, 485-492

3. Yagi, K., Ishida, N., Komura, S., Ohishi, N., Kusai, M., and Kohno, M. (1992) Generation of hydroxyl radical from linoleic acid hydroperoxide in the presence of epinephrine and iron. Biochem. Biophys. Res. Commun. 183, 945-951

4. Schaich, K.M. and Borg, D.C. (1990) Solvent effects in the spin trapping of lipid oxyl radicals. Free Radic. Res. Commun. 9, 267-278

5. Chamulitrat, W., Iwahashi, H., Kelman, D.J, and Mason, R.P. (1992) Evidence against the 1:2:2:1 quartet DMPO spectrum as the radical adduct of the lipid alkoxyl radical. Arch. Biochem. Biophys. 296, 645-649

6. Makino, K., Hagiwara, T., Hagi, A., Nishi, M., and Murakami, A. (1990) Cautionary note for DMPO spin trapping in the presence of iron ion. Biochem. Biophys. Res. Commun. 172, 10731080

7. Fenton, H.J.H. (1898) Note on the oxidation of certain acids in presence of iron. J. Chem. Soc. Proc. 14, 119-120

8. Buettner, G.R. and Oberley, L.W. (1978) Considerations in the spin trapping of superoxide and hydroxyl radical in aqueous systems using 5, 5-dimethyl-1-pyrroline-1-oxide. Biochem. Biophys. Res. Commun. 83, 69-74

9. Buettner, G.R. (1993) The spin trapping of superoxide and hydroxyl free radicals with DMPO (5, 5-dimethylpyrroline-Noxide): more about iron. Free Radic. Res. Commun. 19 supplement, S79-S87

10. Harbour, J.R. Issler, S.L., and Hair, M.L. (1980) Singlet oxygen and spin trapping with nitrones. J. Amer. Chem. Soc. 102, 7778-7779

11. Bilski, P., Reszka, K., Bilska, M., and Chignell, C.F. (1996) Oxidation of the spin trap 5, 5-dimethyl-1-pyrroline $N$-oxide by singlet oxygen in aqueous solution. J. Amer. Chem. Soc. 118, $1330-1338$

12. Tero-Kubota, S., Ikegami, Y., Kurokawa, T., Sasaki, R., Sugioka, K., and Nakano, M. (1982) Generation of free radicals and initiation of radical reactions in nitrones- $\mathrm{Fe}^{2+}$-phosphate buffer systems. Biochem. Biophys. Res. Commun. 108, 10251031

13. Tero-Kubota, S., Ikegami, Y., Sugioka, K., and Nakano, M. (1987) ESR studies on the active intermediate in the enzymatic reduction of the Fe-bleomycine complex. Biochem. Int. 14, 879-887

14. Frejaville, C., Karoui, H., Tuccio, B., Le Moigne, F., Culcasi, M., Pietri, S., Lauricella, R., and Tordo, P. (1995) 5-(Diethoxyphosphoryl)-5-methyl-1-pyrroline $N$-oxide: A new efficient phosphorylated nitrone for the in vitro and in vivo spin trapping of oxygen-centered radicals. J. Med. Chem. 38, 258-265

15. Roubaud, V., Sankarapandi, S., Kuppusamy, P., Tordo, P., and Zweier, J.L. (1997) Quantitative measurement of superoxide generation using the spin trap 5-(diethoxyphosphoryl)-5methyl-1-pyrroline- $N$-oxide. Anal. Biochem. 247, 404-411

16. Clément, J.-L., Gilbert, B.C., Ho, W.F., Jackson, N.D., Newton, M.S., Silvester, S., Timmins, G.S., Tordo, P., and Whitwood, A.C. (1998) Use of a phosphorylated spin trap to discriminate between the hydroxyl radical and other oxidizing species. $J$. Chem. Soc. Perkin Trans 2, 1715-1717

17. Nagata, Y., Yamamoto, Y., and Niki, E. (1996) Reaction of phosphatidylcholine hydroperoxide in human plasma: The role of peroxidase and lecithin: cholesterol acyltransferase. Arch. Biochem. Biophys. 329, 24-30

18. Yamamoto, Y., Brodsky, M.H., Baker, J.C., and Ames, B.N. (1987) Detection and characterization of lipid hydroperoxides at picomole levels by high-performance liquid chromatography. Anal. Biochem. 160, 7-13

19. Chan, H.W. and Levett, G. (1977) Autoxidation of methyl linoleate. Separation and analysis of isomeric mixtures of methyl linoleate hydroperoxides and methyl hydroxylinoleates. Lipids 12, 99-104

20. Janzen, E.G., Jandrisits, L.T., Shetty, R.V., Haire, D.L., and Hilborn, J.W. (1989) Synthesis and purification of 5, 5-dimethyl-1-pyrroline- $N$-oxide for biological applications. Chem.Biol. Interactions 70, 167-172

21. Hamer, J. and Macaluso, A. (1964) Nitrones. Chem. Rev. 64, 473-495

22. McCord, J.M. and Fridovich, I. (1969) Superoxide dismutase. An enzymic function for erythrocuprein (hemocuprein). J. Biol. Chem. 244, 6049-6055

23. Buettner, G.R. (1987) Spin trapping: ESR parameters of spin adducts. Free Radic. Biol. Med. 3, 259-303

24. Nakano, M. (1990) Determination of superoxide radical and singlet oxygen based on chemiluminescence of luciferin analogs in Methods Enzymol (Packer, L., ed.) Vol.186, pp. 585-591, Academic Press, London and New York

25. Finkelstein, E., Rosen, G.M., and Rauckman, E.J. (1980) Spin trapping. Kinetics of the reaction of superoxide and hydroxyl radicals with nitrones. J. Amer. Chem. Soc. 102, 4994-4999

26. Koga, S., Nakano, M., and Uehara, K. (1991) Mechanism for the generation of superoxide anion and singlet oxygen during heme compound-catalyzed linoleic acid hydroperoxide decomposition. Arch. Biochem. Biophys. 289, 223-229

27. Russell, G.A. (1957) Deuterium-isotope effects in the autoxidation of aralkyl hydrocarbons. Mechanism of the interaction of peroxy radicals. J. Amer. Chem. Soc. 79, 3871-3877

28. Dikalov, S.I. and Mason, R.P. (2001) Spin trapping of polyunsaturated fatty acid-derived peroxyl radicals: Reassignment to alkoxyl radical adducts. Free Radic. Biol. Med. 30, 187-197

29. Akutsu, K., Nakajima, H., Katoh, T., Kino, S., and Fujimori, K. (1995) Chemiluminescence of Cypridina luciferin analogues. Part 2. Kinetic studies on the reaction of 2-methyl-6-phenylimidazo [1,2-a] pyrazin-3(7H)-one (CLA) with superoxide: hydroperoxyl radical is an actual active species used to initiate the reaction. J. Chem. Soc. Perkin Trans 2, 1699-1706

30. Ingold, K.U., Paul, T., Young, M.J., and Doiron, L. (1997) Invention of the first azo compound to serve as a superoxide thermal source under physiological conditions: Concept, synthesis, and chemical properties. J. Amer. Chem. Soc. 119, 12364-12365

31. von Sonntag, C. and Schuchmann, H.-P. (1991) The elucidation of peroxyl radical reactions in aqueous solution with the help of radiation-chemical methods. Angew. Chem. Int. Ed. Engl. 30, 1229-1253

32. Stolze, K., Udilova, N., and Nohl, H. (2000) Lipid radicals: Properties and detection by spin trapping. Acta Biochim. Pol. 47, 923-930 